\title{
GIS-Based Spatial Statistical Analysis of Risk Areas for Liver Flukes in Surin Province of Thailand
}

\author{
Ratana Rujirakul $^{1}$, Naporn Ueng-arporn ${ }^{1}$, Soraya Kaewpitoon ${ }^{1}$, Ryan J Loyd ${ }^{1}$, \\ Sarochinee Kaewthani ${ }^{2}$, Natthawut Kaewpitoon ${ }^{3 *}$
}

\begin{abstract}
It is urgently necessary to be aware of the distribution and risk areas of liver fluke, Opisthorchis viverrini, for proper allocation of prevention and control measures. This study aimed to investigate the human behavior, and environmental factors influencing the distribution in Surin Province of Thailand, and to build a model using stepwise multiple regression analysis with a geographic information system (GIS) on environment and climate data. The relationship between the human behavior, attitudes $\left(<50 \% ; X_{111}\right)$, environmental factors like population density $\left(148-169 \mathrm{pop} / \mathrm{km}^{2} ; X_{73}\right)$, and land use as wetland $\left(X_{64}\right)$, were correlated with the liver fluke disease distribution at $0.000,0.034$, and 0.006 levels, respectively. Multiple regression analysis, by equations $\mathrm{OV}=\mathbf{- 0 . 5 9 9}+\mathbf{0 . 0 0 5}$ (population density $\left.\left(148-169 \mathrm{pop} / \mathrm{km}^{2}\right) ; \mathrm{X}_{73}\right)+0.040\left(\right.$ human attitude $\left.(<50 \%) ; \mathrm{X}_{111}\right)+\mathbf{0 . 0 2 2}$ (land used (wetland; X64), was used to predict the distribution of liver fluke. OV is the patients of liver fluke infection, R Square= 0.878, and, Adjust R Square= 0.849. By GIS analysis, we found Si Narong, Sangkha, Phanom Dong Rak, Mueang Surin, Non Narai, Samrong Thap, Chumphon Buri, and Rattanaburi to have the highest distributions in Surin province. In conclusion, the combination of GIS and statistical analysis can help simulate the spatial distribution and risk areas of liver fluke, and thus may be an important tool for future planning of prevention and control measures.
\end{abstract}

Keywords: Risk areas - liver fluke - Surin province - geographic information system - Thailand

Asian Pac J Cancer Prev, 16 (6), 2323-2326

\section{Introduction}

Opisthorchis viverrini is endemic in Thailand and Lao PDR (Sripa et., 2010; Sithithaworn et al., 2012). In Thailand, it is estimated that 6 million people are infected with the $O$. viverrini, particularly in northeastern and northern region (Kaewpitoon et al., 2008a; Kaewpitoon et al., 2008b; Sripa et al., 2010; Sithithaworn et al., 2012). The infection is associated with hepatobiliary diseases including hepatomegaly, cholangitis, fibrosis of the periportal system, cholecystitis, and gallstones (Harinsuta and Vajrasthira, 1960; Harinasuta et al., 1984). The experimental and epidemiological evidences strongly indicate that the liver fluke infection in the etiology of cholangiocarcinoma (Thamavit et al., 1978; IARC, 1994; Sripa et al., 2007). O. viverrini has been classified as Type 1 carcinogens by the International Agency for Research on Cancer, World Health Organization (WHO) (Harinasuta et al., 1984; IARC, 1994).

Geographic information system (GIS) is powerful tool for the storage and management, as well as analysis of natural and cultural data, increasing studies have applied the spatial statistical method of GIS in health sciences, for example, Wattanayingcharoenchai et al., (2011) determined the surveillance characteristics of $O$. viverrini infections in northeast Thailand. The GIS was deployed to overlay the prevalence of disease on urban and agricultural areas as well as manmade land uses. Wongsaroj et al. (2012) studied helminthiasis in Thailand using a GIS. The study results provide evidence that spatial analysis can help to identify patterns of high risk for liver fluke, $O$. viverrini, infestation in order to facilitate prevention and control.

Sonsa and Reungsang (2012) investigated the environmental factors influencing to the distribution, and to build a model using multiple regression analysis with GIS on environment and climate data. This studied, predicted disease distribution map help in identifying areas where vulnerability is high for decision-making and planning in order to prevent or control the spread out of the disease in the future. Therefore, the present study aims to investigate the personal behavior and environmental factors influencing to the distribution in Surin Province of Thailand, and to build a model using multiple regression analysis with geographic information systems on environment and climate data.

${ }^{1}$ Parasitic Infectious Disease Unit, Institute of Medicine, Suranaree University of Technology, ${ }^{2}$ Faculty of Science and Technology, Nakhon Ratchasima Rajabhat University, ${ }^{3}$ Faculty of Public Health, Vongchavalitkul University, Nakhon Ratchasima, Thailand *For correspondence: natthawut.k@hotmail.com,natthawut_kae@vu.ac.th 


\section{Materials and Methods}

Study site

Surin Province, with a total area about $8,124 \mathrm{~km}^{2}$ $(3,137 \mathrm{sq} \mathrm{mi})$, is in northeast Thailand between the Mun River in the north and the Dongrek Mountain chain in the south. Originally it was named Khu Prathai Village by the governor of the city, Luang Surin Phakdi, and used to be an old city of the ancient Cambodians 200 years ago. It is 450 kilometers from Bangkok by road and 420 kilometers by train. The province is subdivided into 17 districts (amphoe). The districts are further subdivided into 158 subdistricts (tambon) and 2,120 villages (muban), 441,922 houses, and 1,381,761 people $(691,425$ males and 690,226 females) (Figure 1).

\section{Data sources}

Descriptive and analytical studies were performed in this study. Data were collected from 2012 and 2013 including: human behaviors (knowledge, attitudes, and practice), were collected by semi-constructive questionnaires. Liver fluke cases were determined from each district (40 cases/districts) by Kato's thick smear, and it is analyzed in a number of cases of patients reported in each district. Health service unit was collected from the Surin provincial public health office, Ministry of Public Health, Thailand.

\section{Environmental data}

The factors are rainfall and temperature recorded by the Northeastern Meteorological Center (Lower center). These data is the accumulation average annual rainfall, and average annual temperature by interpolation of the disease area. The factor of land use recorded by Land Development Department, Ministry of Agriculture and Cooperatives, including some data was collected from the administrative organization of Surin province, Thailand. The land use map is used in 2013 and the land use was classified into agriculture areas, number of houses, water reservoirs, and forest areas.

\section{Statistical analyses}

The relationship between liver fluke and human behaviors (knowledge, attitudes, and practice), health service unit, and environmental factors using statistic analysis by stepwise multiple correlation and significant at p-value at 0.05 , then using multiple regression analysis for correlation and prediction the disease distribution by linear regression equation. The results can validate by $\mathrm{R}$ square. The coefficient of the determination is commonly use statistic to evaluate fit model.

The study protocol was approved by Suranaree University Biotechnological Review Committee, Thailand (2012).

\section{Results}

The $O$. viverrini infection was found in 46 from 680 eligible participants. The infection was found in all district of Surin province. The relationship between the human behaviors with a number of patients of liver fluke infection, found that the human behavior; attitudes, was correlated with the liver fluke disease distribution at 0.000 level, while, the site of health service unit were not correlated with the liver fluke disease distribution. The relationship between the environmental factors; population density (148-169 pop/ $/ \mathrm{km}^{2} ; \mathrm{X}_{73}$ ), was correlated with the liver fluke disease distribution at 0.034 level. Land use factor has significantly correlation between wetland $\left(\mathrm{X}^{64}\right)$, and liver fluke disease distribution at 0.006 level, while, rainfall and temperature were not correlated with the liver fluke disease distribution.

The multiple regression analysis method was used to predict the distribution of liver fluke. Equation following:

$\mathrm{OV}=-0.599+0.005$ (population density $(148-169$ pop $\left.\left./ \mathrm{km}^{2}\right) ; \mathrm{X}^{73}\right)+0.040$ (human attitude $\left.(<50 \%) ; \mathrm{X}_{111}\right)$ +0.022 (land used (wetland); $\mathrm{X}_{64}$ ),

$\mathrm{OV}$ is the patients of liver fluke infection, $\mathrm{R}$ Square= 0.878 , and, Adjust R Square $=0.849$ (Table 1). By GIS

Table 1. The Relationship between Liver Fluke Infection with the Related Factors in Surin Province

\begin{tabular}{lccccc}
\hline Variables & $\mathrm{B}$ & Std. Error & $\beta$ & $\mathrm{t}$ & $\mathrm{P}$ \\
\hline Constant & -0.599 & 0.585 & & -1.025 & 0.324 \\
$\mathrm{X}_{73}$ & 0.005 & 0.002 & 0.305 & $2.372^{*}$ & 0.034 \\
$\mathrm{X}_{111}$ & 0.040 & 0.008 & 0.560 & $4.944^{*}$ & 0.000 \\
$\mathrm{X}_{64}$ & 0.022 & 0.007 & 0.369 & $3.283^{*}$ & 0.006 \\
\hline $\mathrm{R}$ Square $=0.878$ Adjust R Square $=0.849$ & Std. Error of the \\
Estimate $=1.68184$
\end{tabular}

Table 2. Risk Areas of Liver Fluke in Surin Province, Thailand

\begin{tabular}{lcr}
\hline Level of Risk Areas & Areas $\left(\mathrm{km}^{2}\right)$ & \multicolumn{1}{c}{$\%$} \\
\hline Very low risk & $5,254.36$ & 59.41 \\
Low risk & $1,731.05$ & 19.57 \\
Moderate risk & 745.82 & 8.43 \\
High risk & 891.04 & 10.08 \\
Heavy risk & 221.39 & 2.50 \\
\hline
\end{tabular}

Table 3. Distribution of Risk Areas of Liver Fluke in Surin Province, Thailand

\begin{tabular}{|c|c|c|c|c|c|c|}
\hline District & $\begin{array}{l}\text { Very low } \\
\text { risk } \%\end{array}$ & $\begin{array}{l}\text { Loy } \\
\text { risk }\end{array}$ & 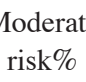 & ris & $\%$ & To \\
\hline Si Narong & .00 & 2.41 & 0.01 & 0.19 & 0.92 & 3.53 \\
\hline Phanom Dong Rak & 1.98 & 0.00 & 0.00 & 0.79 & 0.65 & 3.43 \\
\hline Sangkha & 0.00 & 7.86 & 0.00 & 2.69 & 0.65 & 11.21 \\
\hline Mueang Surin & 10.43 & 0.00 & 0.82 & 0.98 & 0.17 & 12.40 \\
\hline Non Narai & 1.50 & 0.00 & 0.18 & 0.37 & 0.06 & 2.11 \\
\hline ng Thap & 2.82 & 0.00 & 2.04 & 0.08 & 0.04 & 4.97 \\
\hline on Buri & 3.91 & 0.00 & 0.00 & 3.48 & 0.01 & 7.41 \\
\hline Rattan & 5.89 & 0.00 & 0.58 & 0.00 & 0.01 & 6.48 \\
\hline Prasat & 9.78 & 0.00 & 1.30 & 0.00 & 0.00 & 11.08 \\
\hline Sikhoraphum & 7.93 & 0.00 & 0.32 & 0.00 & 0.00 & 8.26 \\
\hline Kap Choeng & 4.30 & 0.00 & 2.16 & 0.00 & 0.00 & 6.46 \\
\hline Chom Phra & 3.28 & 0.00 & 0.46 & 0.00 & 0.00 & 3.74 \\
\hline Buachet & 3.23 & 0.00 & 0.24 & 0.08 & 0.00 & 3.54 \\
\hline Sanom & 2.29 & 0.00 & 0.13 & 0.00 & 0.00 & 2.42 \\
\hline Khw & 2.07 & 0.00 & 0.18 & 0.00 & 0.00 & 2.25 \\
\hline Lamduan & 0.00 & 2.33 & 0.00 & 0.14 & 0.00 & 2.47 \\
\hline Tha Tum & 0.00 & 6.97 & 0.00 & 1.28 & 0.00 & 8.25 \\
\hline Total & 59.41 & 19.57 & 8.43 & 10.08 & 2.50 & 100.00 \\
\hline
\end{tabular}




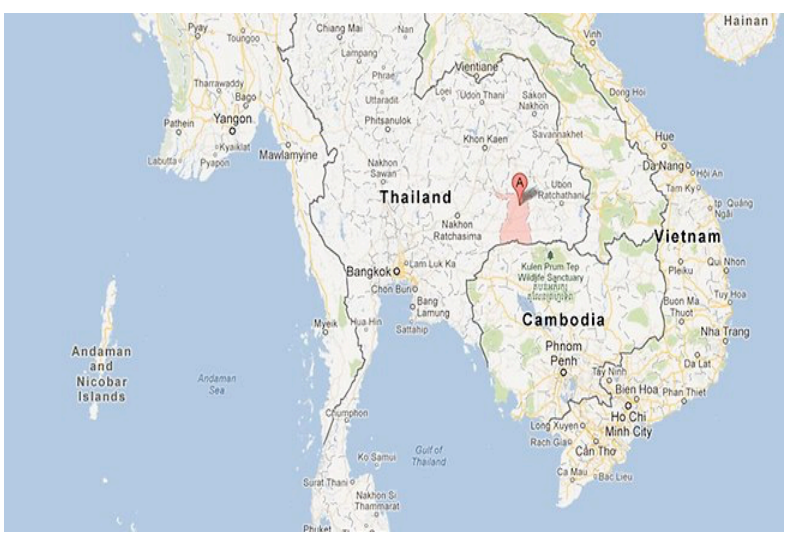

Figure 1. A Google Map Showing the Location of Surin, Thailand

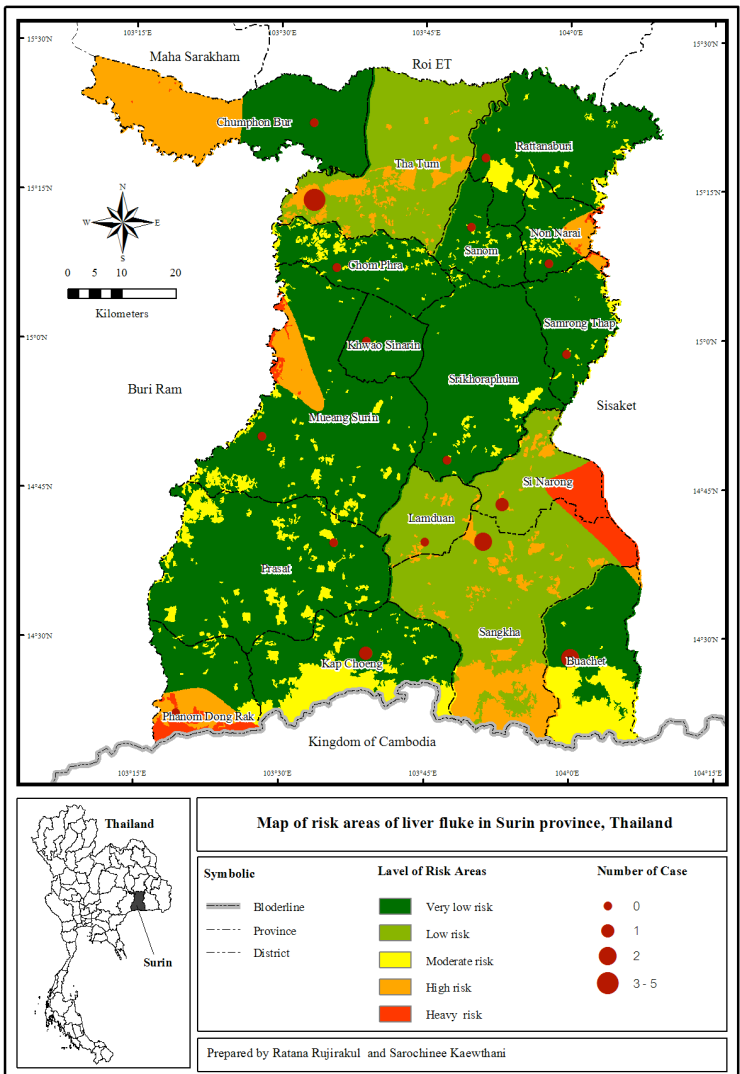

Figure 2. Map of Risk Areas of Liver Fluke in Surin Province, Thailand

analysis, it was found that Si Narong, Sangkha, Phanom Dong Rak, Mueang Surin, Non Narai, Samrong Thap, Chumphon Buri, and Rattanaburi have the highest distribution of the parasite Surin province (Table 2, 3, Figure 2). By equation, it was found population density (148-169 pop $\left./ \mathrm{km}^{2}\right)$, human attitude $<50 \%$, land used; wetland were effect on the disease dispersion.

\section{Discussion}

$O$. viverrini is still a major public health problem in Thailand (Sripa et., 2010). The infection is associated with cholangiocarcinoma (Thamavit et al., 1978; IARC, 1994; Sripa et al., 2007). Prevention and control are needed in order to decrease the morbidity and mortality of this disease. GIS was applied to potential surface analysis of risk areas for liver fluke infection in the present study. This study found that these factors associated with liver fluke distribution. By GIS analysis of the factors found that population density is statistically related to liver fluke infection. This data is surprising, however, it may be suggested that people who live in the same community, culture, socio-economic stratum, etc. have an increased chance to consume the raw fish containing liver flukes. Human attitudes were related to liver fluke infection in this study is similar to other published research that showed a high risk of infection in people who had risky behavior and attitudes, mainly frequently eating raw Cyprinoid fish in endemic areas (Kaewpitoon et al., 2007; Kaewpitoon et al., 2012b; Kaewpitoon et al., 2012c). Present study has indicated that wetlands are endemic areas for liver flukes in the northeastern and northern regions of Thailand. Wetlands are an appropriately ecosystem for the life cycle of liver flukes, especially since they have a high population of Bithynia snails (the $1^{\text {st }}$ intermediate host) and cyprenoid fish (the $2^{\text {nd }}$ intermediate host of liver flukes) (Wykoff et al., 1966; Vichasri et al., 1982; Sadun,1995; Sithithaworn et al., 1997; Jongsuksuntigul and Imsomboon, 2003; Sripa et al., 2010; Sithithaworn et al., 2012). Present study result is similar to Wattanayingcharoenchai et al. (2011), found the farmland were highly related to the infection. The present study is the first to determine the risk areas in Surin province, Thailand. The area of Surin province that was risk stratified covered 17 districts and the heavy risk area covered 8 districts including Srinarong, Sangkha, Phanom Dongruk, Mueang Surin, Non Narai, Samrongthab, Chumphon Buri, and Ratanaburi. These areas require campaigns to address health behaviors and attitudes. Moreover, people in these areas should be screened for cholangiocarcinoma.

The present study identifies the increased risk areas for liver flukes in Surin province and may useful for future planning of prevention and control measures.

\section{References}

Harinasuta T, Riganti M, Bunnag D (1984). Opisthorchis viverrini infection: pathogenesis and clinical features. Arzneimittelforschung, 34, 1167-9.

Harinasuta C, Vajrasthira S (1960). Opisthorchiasis in Thailand. Am J Trop Med Hyg, 54, 100-5.

IARC (1994). Infection with liver flukes (Opisthorchis viverrini, Opisthorchis felineus and Clonorchis sinensis). IARC Monogr Eval Carcinog Risks of Hum, 61, 121-75.

Jongsuksuntigul P, Imsomboon T (2003). Opisthorchiasis control in Thailand. Acta Trop, 88, 229-32.

Kaewpitoon N, Kaewpitoon SJ, Pengsaa P, et al (2007). Knowledge, attitude and practice related to liver fluke infection in northeast Thailand. World J Gastroenterol, 28, 1837-40.

Kaewpitoon N, Kaewpitoon SJ, Pengsaa P(2008a). Opisthorchis viverrini: the carcinogenic human liver fluke. World $J$ Gastroenterol, 7, 666-74.

Kaewpitoon N, Kaewpitoon SJ, Pengsaa P, et al (2008). Opisthorchiasis in Thailand: review and current status. World J Gastroenterol, 21, 2297-302.

Kaewpitoon SJ, Rujirakul R, Ueng-Arporn N, et al (2012b). Community-based cross-sectional study of carcinogenic human liver fluke in elderly from Surin province, Thailand. 
Asian Pac J Cancer Prev, 13, 4285-8.

Kaewpitoon SJ, Rujirakul R, Kaewpitoon N (2012c). Prevalence of Opisthorchis viverrini infection in Nakhon Ratchasima province, Northeast Thailand. Asian Pac J Cancer Prev, $13,5245-9$.

Sadun EH (1995). Studies on Opisthorchis viverrini in Thailand. Am J Hyg, 62, 81-115

Sithithaworn P, Andrews RH, Nguyen VD, et al (2012). The current status of opisthorchiasis and clonorchiasis in the Mekong Basin. Parasitol International, 61, 10-6.

Sithithaworn P, Pipitgool V, Srisawangwong T, et al (1997). Seasonal variation of Opisthorchis viverrini infection in cyprinoid fish in north-east Thailand: implications for parasite control and food safety. Bull World Health Organ, 75, 125-31.

Sonsa A, Reungsang P (2012). A spatial analysis of liver fluke diseases distribution using GIS in Khon Kaen province, Thailand. The 33rd Asian conference on remote sensing, November 26-30 At Ambassder city Jomtien hotel, Pattaya, Thailand.

Sripa B, Kaewkes S, Intapan PM, et al (2010). Food-borne trematodiases in Southeast Asia: epidemiology, pathology, clinical manifestation and control. Adv Parasitol, 72, 305-50.

Sripa B, Kaewkes S, Sithithaworn P, (2007). Liver fluke induces cholangiocarcinoma. PLoS Med, 4, 201.

Thamavit W, Bhamarapravati N, Sahaphong S, et al (1978). Effects of dimethylnitrosamine on induction of cholangiocarcinoma in Opisthorchis viverrini-infected Syrian golden hamsters. Cancer Res, 38, 4634-9.

Vichasri S, Viyanant V, Upatham ES (1982). Opisthorchis viverrini: intensity and rates of infection in cyprinoid fish from an endemic focus in northeast Thailand. Southeast Asian J Trop Med Public Health, 3, 138-41.

Wattanayingcharoenchai S, Nithikathkul C, Wongsaroj T, et al (2011). Geographic information system of opisthorchis viverrini in northeast Thailand. Asian Biomedicine, 5, 687-91.

Wongsaroj T, Nithikathkul C, Reungsang P, et al (2012). Geographic information of helminthiasis in Thailand. International J Geoinformatics, 8, 59-64.

Wykoff DE, Chittayasothorn K, Winn MM (1966). Clinical manifestation of Opisthorchis viverrini infection in Thailand. Am J Trop Med Hyg, 15, 914-8. 